\title{
RECORDAR E ESQUECER
}

\author{
José Luis Villacañas Berlanga
} Universidad de Murcia 



\section{UNHA HISTORIA ARQUETÍPICA}

Apenas tres meses despois de que Paul Gaugin morrera, tras deixar o mercado europeo inundado de estampas idílicas das illas Tahití, un viaxeiro, médico da mariña mercante francesa, chegaba a esta illa seducido polo paraíso que os marchantes do pintor lle presentaran ao mundo enteiro. Froito da súa estadía entre os nativos foi a súa novela Les Immémoriaux, na que o autor, Victor Segalen (1956 e 2000) ${ }^{1}$, comprendeu que compartía o destino dos que o precederan na súa tarefa. Como todos eles, ía falar do paraíso unicamente para recordar a expulsión. Todo o que puido atesourar na súa experiencia literaria foi ese proceso de cambio de mentalidade dun pobo enteiro que, tras a predicación cristiá e a irrupción do home branco, esquecera completamente a súa alma. En boca dun dos últimos nativos, Paofai, o derradeiro resistente fronte á esixencia de cambiar as súas vellas tradicións por aquelas novas historias narradas no Gran Libro, pronunciou daquela esta queixa: «Onde están os hombres Maori? Non coñezo xa ningún. Cambiaron de pel».

Pero, en realidade, a pel seguía a ser a que era. O detalle non debe pasar desapercibido. A derradeira expresión da resistencia cultural realízase na linguaxe propia da cultura que morre. Cambiar a alma, as tradicións, os relatos, as leis, os deuses e as palabras é para o nativo Paofai cambiar de pel. O máis interior resumíase para el no puramente exterior. O que fai recoñecibles os homes está concentrado na pura e núa superficialidade. Se os seres humanos xa non son recoñecibles, daquela, e aínda que cambiaran a súa alma, en realidade cambiaron de pel.

Con esta núa expresión de radical descoñecemento non se podía escribir unha novela. Segalen, como Gaugin, quería deixar testemuño do que se ía, e por iso se

\footnotetext{
${ }^{1}$ Para Victor Segalen cómpre ter en conta o volume de Giller Mauceron (1991) e o número de Cahier de l'Herme de 1998.
} 
entregou a unha actividade especificamente occidental. Debemos recordar que o mito fundador da nosa cultura reside na melancolía: o paraíso queda atrás e a nosa vida consiste na procura do tempo perdido e na reconstrución do Edén. Desde a ciencia ata a psicoanálise, desde a política ata a arte, por todas as partes aparece a mesma promesa: o que perdemos non está definitivamente perdido. Deste impulso xorde a novela de Segalen: narrando o proceso de esquecemento e de perda, cando menos lógrase recordar e conservar algo. Os exemplos poden despregarse ao infinito. Cando se inicia $\grave{A}$ la recherche du temps perdu, o narrador colócase nese instante anterior no que somos gañados polo sono e perdemos a conciencia. Ao narrar ese momento, Proust cre captar o tránsito máxico no que se lembra e que se ve a un tempo, no que todo se presenta ante a imaxinación coa nitidez da vivencia orixinaria. Nese pórtico desexa situarse a memoria. Cando ao final da novela Os desmemoriados, un rapaz nativo, Auté, chega á illa e reclama que se lle expliquen as vellas historias sobre os primeiros seres humanos que como el chegaron á terra de Haiti, o cristianizado Iakoba di: "Un sacerdote, do que non lembro o seu nome, contoume unha vez algunhas cousas». Daquela, e ante os rogos do rapaz, con dificultade recorda os murmurios que o derradeiro sacerdote maorí, enfermo e moribundo, lle dedicou. Malamente pode dicir que no principio de todo había un deus e que «era o seu nome Taàroa. Estaba na inmensidade. Nada de terra, nada de ceo, nada de mar, nada de homes». E cando con urxencia se lle pide que continúe, Iakoba, con medo de que o misioneiro cristián se decate de que volveu relatar historias dos vellos deuses, só pode dicir «Taàroa chama e non responde ninguén». $\mathrm{O}$ complexo de culpa propio da transición queda claro. Non se trata de que o vello deus morrera, senón de que Iakoba, un maorí cristianizado, xa non responde. $\mathrm{O}$ deus quedou sen fieis. Asombrado, Auté lembra o oficio do verdadeiro sacerdote: «Pensaba que a túa memoria era infalible», dille. E daquela o cristianizado sorrí e cun ton triunfal asegura: "Si que o é, pero non quero gastar palabras para conservar os relatos antigos. Quero usalas todas para custodiar as historias do verdadeiro Deus. Podo recitar xa a metade do libro de Xoané. Pero cando o home enfermo, en Opoa, me contaba estas historias súas, eu durmía. Por iso non o recordo». Asombrado o rapaz polo feito de que todo se xogara nun momento de azar e de sono, reclámalle que por que non lle esixiu que lle repetise as lendas cando espertou. Iakoba confesa que "cando espertei, el estaba morto ou case morrendo». No momento de solemnidade maior da novela di: 
«Daquela as palabras morreron con el». Logo, o resistente Paofai guíndalle o peor insulto que se lle pode dirixir a un sacerdote: «Home sen memoria. Perdiches as palabras». Mais o cristián Iakoba comprende que este é un caso máis de ofensa que, segundo o novo Deus Kerito -refírese a Cristo-, el debe perdoar.

\section{COMUNIDADES DE TRANSMISIÓN}

Agora inicio o meu segundo punto. Teño que confesar que non pretendín documentarme sobre as últimas tecnoloxías de protección e conservación, nin pasar polo que non son. As miñas únicas ocupacións son a historia intelectual e mais a filosofía política e para todos os efectos a miña perspectiva é a daqueles vellos saberes liberais que logo foron coñecidos como humanistas. A miña reflexión non será tecnolóxica nin concreta, senón que padecerá desa lamentable xeneralidade en que nos movemos os filósofos. O máis concreto que escoitarán de min é esta historia ficticia inserida nunha novela de principios do século XX. A nosa esperanza pasa por falarlles aos que queiran ser algo máis que especialistas, pero nesta ocasión o meu traballo será máis doado porque falo con axentes públicos cuxa ética profesional é moi próxima á miña. En realidade, todos queremos evitar que a acusación de Paofai, "Home sen memoria. Ti perdiches as palabras", recaia sobre nós. Para avanzar nese intento de definir a nosa ética profesional, e a nosa responsabilidade, daquela será mellor que volvamos ao relato de Segalen.

Se insistín neste relato é porque sitúa con plasticidade o tema da memoria no terreo en que o desexo afrontar. Polo demais, a escena decisiva describe perfectamente todas as dimensións do que Connerton chamou un act of transfer (1989), coa súa performatividade, neste caso frustrada. Como é natural, a novela está construída sobre unha radical contraposición cos outros dous relatos fundadores da tradición cultural occidental. En Opoa, un lugar insignificante das illas Tahití, un vello sacerdote moribundo pronuncia por derradeira vez as historias sagradas ante un mozo que as debía conservar. Por desgraza, este xa está cristianizado e esas historias non lle interesan. Así que queda durmido. Cando esperta, o narrador morreu ou vai morrer pronto. No instante en que se xogaba o destino da transmisión cultural, o home quedou durmido e con esta actitude produciu a fractura na transmisión cultural. Nin Sócrates nin Cristo tiveron esta 
desgraza. Occidente fúndase sobre outras escenas. No momento das súas mortes, os discípulos de Sócrates ou os de Cristo estaban espertos e ben espertos, de tal maneira que puideron narrar as últimas palabras do mestre, e darlles con elas completo sentido ás súas vidas. Sobre esas vidas exemplares, as testemuñas oculares puideron escribir as noticias e as sentenzas, as palabras e os acenos. Entre eles, aqueles que falaban da necesidade de velar e estar espertos, pois o tempo é o inimigo que vén coma un ladrón para furtarnos a facenda. Occidente sempre estivo alerta e coñeceu tanto a fraxilidade do humano como a relevancia do act of transfer.

En efecto, se algo caracterizou a melancólica cultura occidental está nesta conciencia do poder do tempo. Ese poder maniféstase ante todo mediante unha relativa desvalorización do orixinario. Unha vez máis, o mellor estivo no pasado. Foi un instante e caracterizou a orixe. Cronos arráncanos pola forza do peito da nai e devóranos tan pronto como nos descobre. Esa conciencia mitolóxica é constitutiva así mesmo do cristianismo ${ }^{2}$ e do platonismo, que lle deben o seu éxito a que intentaron ofrecer unha resposta adecuada á insoportable melancolía que implica unha perda radical. Este asunto ten que ver co noso tema. Pois o máis curioso das respostas platónica e cristiá - tan próximas- reside en poñer de manifesto así mesmo a necesidade e a limitación das tecnoloxías da lembranza. A conciencia desa ambigüidade da técnica da lembranza -algo necesario e ao mesmo tempo limitado- aféctanos hoxe tanto como hai vinte e cinco séculos e, por iso, este tipo de xeneralidades intemporais son as preferidas do filósofo. $\mathrm{O}$ seu papel reside en recoñecernos, en comprender que o novo non o é tanto.

E, efectivamente, o logos platónico sabía que o proceso de lembranza pode quedar desvalorizado co tempo e que cómpre fixar o relevante e esencial no texto escrito para loitar contra o esquecemento. A escritura como técnica da lembranza marcou o destino de Occidente, como sabemos. Así e todo, tanto os platónicos como os cristiáns pronto comprenderon que o texto escrito quedaba morto, como os deuses de Haití, cando alguén non respondía ante eles. A súa soa presenza non garantía a transferencia de sentido. O único que garantía esa transferencia era a continuidade do espírito e este só tiña un soporte: os seres

2 Cfr. o traballo de Franco Motta (2007, p. 712-734). Na mesma liña, A. Destro e M. Pesce (2000), D. Hervieu-Léger Hervieu-Léger (1993) e Stroumsam (1999). 
humanos. Necesidade da técnica e limitación da técnica. Sempre igual. Sobre eses textos canónicos era preciso reflexionar de forma continua ata conquistar unha experiencia tan fiel como a da orixe, como a do primeiro que os escribiu, fose Platón, Mateo ou Xoán. Os primitivos cristiáns sabían que a virtude dos apóstolos non se podía repetir, pero que coa lectura dos textos evanxélicos era posible ter unha imaxe daquela virtude e volver encarnala, logrando recibir a graza. Así que era preciso escribir e asegurarse contra o tempo e a súa decadencia -non ser devorados por el-; pero esa seguridade técnica, a escritura ou o arquivo, non vencía o tempo per se. A tecnoloxía da escritura era unha consecuencia da decadencia, un seguro contra o esquecemento, pero non a vence nin por si soa produce a lembranza. A mera tecnoloxía non era a promesa, senón un simple medio. Só o espírito, a comunidade de seres humanos reunidos pola filia platónica ou a caritas cristiá, recoñecidas por un ethos concreto, seres humanos crecidos na lectura dos textos pero que as podían vivir por si mesmos, só esa experiencia de graza vencía o tempo e ofrecía un presente pleno. Escribir e lembrar - «facede isto en memoria de min», como di a liturxia católica- ou dialogar sobre os problemas dos textos, como impón a regra platónica, era unha mediación técnica para forxar unha comunidade humana baseada na experiencia presente do espírito. Esta experiencia consiste en saber que están xuntos por medio dunha vivencia poderosa que une o pasado orixinario con este presente pleno. A forma comunitaria vincula memoria con éxtase, pasado e presente e desde aí gaña a súa potencia expansiva. Só esas vivencias vencen o tempo dentro do tempo e ábrenlle unha porta a algo que se experimenta como eternidade, iso que pode aspirar a ser un "perpetuo presente» (Motta, 2007, p. 713), algo que con menos vontade de transcendencia poderiamos chamar valioso en si. Por moito que non poida durar, esas certezas ofrecen un anticipo de que o poder do tempo non é definitivo nin supremo. O tempo é o veo de Maya. Sabemos que pode ser riscado. A melancolía, a conciencia da decadencia, tan deprimente, non é o tráxico estado definitivo do ser humano. Cronos non é o soberano. Esta é a mensaxe da filosofía e do cristianismo. A súa verosimilitude reside na capacidade de fundar comunidade e resistir o esquecemento con algo máis que unha eficaz lembranza. Trátase dunha experiencia verdadeira que outorga un novo presente ao pasado. Sen comunidades de transmisión, dotadas dun ethos específico, esas experiencias e esa reactualización do pasado estarían perdidas. 


\section{MEMORIA MORAL}

Nun volume moi completo dedicado ao tema, editado en 2007 e reunido por Elena Agazzi, Vita fortunati, dise que, desde os anos noventa ao día de hoxe, coñecemos unha obsesión polo pasado e unha hipertrofia da memoria (1007, p. 9). Ambos os dous fenómenos foron explicados pola aceleración do tempo histórico presente, os profundos cambios sociais, a unificación e homoxeneización das formas de vida e o desarraigamento universal. Estes fenómenos diminúen a capacidade das institucións vixentes de garantir a continuidade temporal e a transmisión creadora de sentido ${ }^{3}$. Se unha comunidade é unha síntese de memoria e éxtase presente, a insistencia na memoria suxire a falta de evidencias da comunidade no presente. Todos eses cambios acelerados implican, de feito, a destrución das comunidades tradicionais. A insistencia na memoria é o síntoma dun estado melancólico xeral, dominado pola conciencia de perda. Furgamos unha e outra vez no pasado para intentar recuperar algo. Este fenómeno pódese describir doutra maneira. A aceleración lévanos a un futuro cada vez máis ignoto e, para ocultar a ansiedade que isto nos produce, falamos cada vez máis do pasado. Así que a hipertrofia da memoria sería un intento desesperado por vivir nun escenario familiar para escapar dun futuro completamente estraño. A nosa relación co futuro estaría determinando a nosa relación co pasado. Sempre é así, pois o futuro é o verdadeiro ordenador da memoria. Un futuro ignoto xera unha memoria hipertrofiada, desordenada, pois non sabemos que será o relevante dela para un futuro que descoñecemos ${ }^{4}$. Canto máis inquietude, máis necesidade de memoria (Leccardi, 2005, p. 117-134). Ante a fraxilidade endémica dos grupos humanos, máis intentamos producir grupos mediante o intento de lembrar en común. O feito de que entre as noticias dos telexornais -que deben xerar unha percepción común do mundo- se introduzan miniespazos para ordenar a

${ }^{3}$ A análise da aceleración, moi coñecida desde a obra de R. Koselleck, foi despregada e sistematizada por C. Leccardi (2005, p. 49-85).

${ }^{4}$ Cfr. as reflexións de L. Sciolla (2005, p. 19-30), que subliñou, no sentido en que xa argumentaba R. Koselleck (1993), que só hai responsabilidade onde se reconstrúe dalgunha maneira a continuidade do tempo, as tres dimensións do tempo: un é responsable das accións do pasado e das consecuencias do futuro, e isto ante os seres humanos do presente. Neste sentido, é a propia responsabilidade a que crea o tempo común. Este sería unha estrutura ética, non unha forma da sensibilidade nin un resultado epistemolóxico da experiencia. 
memoria suxire de forma clara que a nosa sociedade non pode vivir só sobre unha experiencia do presente, cada vez mudable, e que require, para dotarse de sentido da continuidade, a selección de lembranzas para establecer un pasado común. Reflexionemos agora sobre este pequeno problema: que a memoria é un elemento imprescindible da formación dos grupos humanos. Non hai que esquecer que tamén os grupos humanos son os lugares do poder. Ter isto en conta permitiulle a Ana Lisa Tota dicir que «o estudo do pasado coincide fundamentalmente coa análise das formas de articulación do poder» (2007, p. 113). O ethos que buscamos para a nosa humilde comunidade de transmisión, en certo modo, sempre implica unha forma de exercer un poder, por pequeno que este sexa.

Permítanme facer unha pequena digresión, que orientará tamén a nosa intervención. A memoria é un vello mecanismo evolutivo destinado a mellorar as prestacións dos organismos e ten unha tradución biolóxica niso que se chama memoria inmunolóxica. Sabemos que determinados dispositivos biolóxicos en contacto cun axente patóxeno, tras producir os anticorpos necesarios de forma masiva, matan case todos estes eficaces anticorpos agás un conxunto limitado de axentes que conservan o pattern, o esquema do axente patóxeno, de tal forma que este pequeno corpo de elite pode facerlle fronte ao vello inimigo, no caso de que se presente outra vez, con celeridade e eficacia. A memoria cultural é un expediente humano moito máis recente, e foi destinado a mellorar as prestacións deses organismos que son os grupos humanos. Esta innovación da memoria cultural, desde o bisonte de Altamira, producida pola linguaxe e as súas técnicas, asegurou a hexemonía do ser humano sobre as demais especies. Pero, da mesma maneira que a memoria inmunolóxica, a memoria simbólica debería gardar eses corpos de células con memoria dos patóxenos para activarse no caso de que novos axentes hostís ameazasen os grupos humanos e os puxesen en perigo. A nosa pregunta é se o sistema inmunolóxico cultural logrou unha memoria tan eficaz coa inmunolóxica. Desde os estudos pioneiros de Richard Semon e Aby Warbung sobre a "pegada» psíquica de certas imaxes, os estudos culturais continúan preguntándose sobre este asunto ${ }^{5}$.

5 "Der Leidschatz der Menschheit wird humaner Besitz», Aby Warbug, Notiz zur einem Vortrag in der Hamburger Handelskammer, Londres, The Warburg Institute, 10 abril de 1928, número de arquivo 12.27, citado por A. Assmann (2002, p. 412). Para as relacións con Semon e a súa teoría do «engrama» debemos consultar E. H. Gombrich (1970). Hai tradución castelá en Alianza Universidad. 
Non é unha casualidade que o novo interese verbo do problema da memoria proveña da necesidade de asegurar o estatuto único da Shoa, o da memoria do peor axente patóxeno da humanidade. Como a comunidade dos amigos de Sócrates, ou a dos deprimidos apóstolos, rodeados de poderes hostís, temían que o crime perpetrado sobre o fundador quedase esquecido e se disolvese a comunidade de testemuñas do fundador, así a comunidade xudía quixo asegurar a súa propia supervivencia mediante a lembranza desa vontade radical de exterminala que foi o Holocausto. A memoria da Shoah, como a de Sócrates e a dos apóstolos, debía sobrevivir ás testemuñas oculares. É a única garantía de que despois de mortos a súa experiencia sexa transmitida. O momento da transmisión non debía atopar os xudeus durmidos, como acontecía na novela de Segalen. Ese foi o sentido último da película de Claude Lanzmann.

Debémoslle, entre outros, a J. Assmann, e os seus estudos sobre Moisés e a memoria do monoteísmo ${ }^{6}$, o inicio desta liña de traballo, que continuou A. Assmann (1999). A fortaleza desta comprensión procede do seu valor moral. Unha comunidade que aínda é perseguida en moitos lugares, desprezada noutros e soportada en moitos, que leva sobre si unha profunda historia de hostilidade e humillación, debía manterse firme na lembranza do Holocausto para identificar nas primeiras manifestacións de antisemitismo o perigo que pode levar ás últimas consecuencias. O Holocausto é a memoria do que non pode ser consentido baixo ningunha razón. O potencial moral da memoria do Holocausto, separada do seu propio momento histórico, amplíase ata converterse nun relato que lle afecta ao xénero humano na súa totalidade. É unha comunidade universal a que xorde desa lembranza, e sen ela non podemos entender o discurso dos dereitos humanos. Xa un filósofo como Benjamin xeneralizara a historia como tempo de violencia e de masacre e quixo proxectar o estatuto de xudeu respecto á inmensa maioría do xénero humano -a verdadeira humanidade sufrinte. Así, Shoa simboliza non só a comunidade xudía, senón a condición humana humillada. $\mathrm{O}$ que se lle podía inflixir ao ser humano sempre comezaba por ferir o xudeu, pero os poderes que se levantarían sobre ese sufrimento non se limitarían a este momento inicial.

${ }^{6}$ Débeselle a el, xunto con Tonio Hülscher, o colectivo inicial Kultur und Gedächtnis, Frankfurt, 1988. En Akal foi traducido o libro Moisés o exipcio, que fai a historia do monoteísmo xudeu ata Freud. 
Esa memoria da Shoah é a última expresión do monoteísmo moral propio do xudaísmo posterior ao Templo que aínda alcanzou a E. Cohen, o mestre común de Benjamin e de Ortega. Ese monoteísmo moral é o que se pon en acto cada vez que se recupera a lembranza das vítimas inocentes, desde Guatemala a Camboia, desde Rusia a Sudáfrica. Só podo invocar aquí os traballos relacionados coa xustiza transicional, e a imposibilidade de constituír un grupo humano en condicións de vivir xunto se non se atenden estas dimensións da memoria das vítimas. Sen esta lembranza, destinada a impedir a súa repetición, o mundo civil na súa totalidade padece un desastre. Un trauma sempre necesita reparación a través dun traballo de recordo cuxa divisa é que non hai futuro sen perdón, pero tampouco perdón sen verdade. O que se esquece non pode ser perdoado. Como dicían as vítimas do Apartheid e recolle o bispo Desmond Tutu: «queremos perdoar pero non sabemos a quen» (1999, p. 114) $)^{7}$. O trauma padecido necesita recoñecemento e visibilidade. Non obstante, o propio do trauma reside en que non é testemuñable na súa experiencia polas vítimas. De aí que moitas veces só o sufrimento dos fillos poida revelar o que aconteceu ${ }^{8}$. En todo caso, sen perdón non hai grupo, senón escisión. Sen a memoria moral non hai posibilidade de formar grupos humanos. Sen a confesión previa do perdón, a verdade e a memoria poden dispoñerse a servir as potencias non morais da vinganza. Parece que esta memoria moral exemplar, no concepto de T. Todorov (1995), forma parte do ethos da nosa comunidade de transmisión.

\section{MEMORIA POLÍTICA}

Pero a humanidade en nós non é o único grupo que, cando se sente en perigo, xera unha memoria moral. Hai outra memoria política, memoria das comu-

\footnotetext{
${ }^{7}$ O procedemento da Comisión pola verdade e a reconciliación (Thruth and Reconciliation Commision) consistiu en propoñer a amnistía para aqueles que contribuísen a descubrir a verdade mediante a asunción de responsabilidades.

${ }^{8}$ Cfr. o traballo de Renate Siebert (2007, p. 79-99), que lle dedica unha análise á falta de produtividade moral do silencio. «Entre a memoria e a xustiza, está a palabra», afirma (2007, p. 87).
} 
nidades políticas, de natureza politeísta, que senten o perigo dun mundo que se fai cosmopolita, por un lado, mentres se orquestra ou se interpreta sobre a diferenza amigo-inimigo, por outro lado. Non é un azar que a memoria da Shoa implique unha impugnación deste tipo de memoria tecnicamente elaborada polos Estados nacionais para producir a comunidade nacional fortalecida no presente con experiencias identitarias comúns. Estas memorias nacionais adoitan implicar que o caracterizado como inimigo perda a súa condición de humanidade e que se proxecten sobre el o tipo de sentimentos que o antisemitismo tradicional proxectou sobre os xudeus ${ }^{9}$. A relación entre memoria e nación resulta cuestionada desde o paradigma da Shoah, pois esas fortes experiencias comunitarias destinadas á produción de identidade política $-\mathrm{o}$ espírito nacional- están na base das experiencias de desprezo, violencia, hostilidade e crime respecto ao outro. Hoxe sabemos que unha identidade forte, autosuficiente, homoxénea, activa, non pode considerar a quen decide que é outro, senón como un inimigo. Memoria ao servizo da identidade, da diferenza como hostilidade: ese é o vello esquema do Estado-nación que ten a súa última consecuencia na Shoah. A consecuencia é considerar un paria o que non pertence á nación, e o paria, no momento de perigo, é unha ameaza de traizón. O que non queira falar de nacionalismo, xa que logo, debería calar sobre o antisemitismo. O que denuncie o Holocausto debería denunciar esas formas políticas que nos predispoñen a matar o outro co desprezo radical de quen atenta contra alguén indigno. $\mathrm{O}$ nacionalismo atopa no antisemitismo o seu modelo e en moitos casos foi construído sobre el. E para estes efectos é indiferente que o nacionalismo sexa de Estado ou dun pobo sen Estado. Nun caso e noutro impugna a conciencia moral depositada na memoria da Shoah e sitúanos na senda da depuración e a construción violenta de homoxeneidade. O lexítimo da memoria da Shoah reside en que aínda encerra un núcleo de universalismo e denuncia no antisemitismo un atentado contra a humanidade no corpo dos xudeus,

\footnotetext{
${ }^{9}$ Para esta mitoloxía política das nacións hai unha literatura moi abundante (Bielefeld e Engel, 1998; Assmann, 1998, p. 379-400; Harth e Assmann, 1992). Para o mito nazi, como contrapartida da Shoa, pode verse S. Behrenbeck (1996). Na literatura inglesa é importante o libro de C. Flood (1996). Que no fondo estes mitos nacionais xurdiron da proliferación da mítica xudía do pobo elixido, pode verse en A. D. Smith (2003).
} 
non un atentado contra os xudeus en tanto xudeus. Pois o verdadeiramente propio do xudeu, como puxo de manifesto Brett Levinson, é que pode ser como outro calquera (2004, p. 9-29).

Os procesos de integración supraestatais e os procesos de homoxeneización mundial ameazan o vello sentido de continuidade das nacións-Estado. $\mathrm{O}$ universalismo do mercado e das formas de vida xera tal sensación de ameaza que os grupos políticos senten unha necesidade imperiosa de rescatar unha memoria capaz de consolidalos. Os Estados nacionais responderon a este proceso coa renovación da memoria museística, con estratexias expositivas novas, con sociedades de celebracións e demais. Estas intervencións xeraron unha política de conmemoracións, unha historia oficial que se constrúe sobre decisións verbo do que cómpre esquecer e lembrar. Pero non só. A aura do poder presenta esta historia con rituais próximos á sacralización, pero tamén cunha vontade de eficacia sentimental que linda na banalización. Con iso, xérase un patrimonio común de memoria que é un acto político de afirmación (Tota, 2007, p. 102-112). Así xorden os canons consolidados. Pola súa parte, os grupos nacionais minoritarios responden con mimetismo a estes procesos porque saben que teñen un dobre inimigo: os procesos universais e as afirmacións estatais. Esta experiencia faille dicir a Pierre Nora, autor como saben vostedes dun dos máis importantes estudos sobre o campo: Les lieuxs de la mémoire: «Fálase da memoria só porque non existe» (1984-1992); é dicir, porque ten que ser construída. Do que realmente falaba Nora era da memoria vinculada ao Estado-nación e o seu traballo tiña como meta a análise dos procesos de recomposición da identidade nacional francesa. En realidade, esta liña procedía dos discípulos de E. Durkheim e coma el aspiraban a definir o espírito da república ${ }^{10}$. Pero ao pouco que teñan poder, os grupos minoritarios deixaranse levar por estes mesmos procesos.

Estes procesos son moi complexos e teñen moito de valioso na defensa de formas de vida concretas, de tradicións culturais, de linguas ameazadas, de garantir a heteroxeneidade e a vida integrada en espazos e paisaxes. $\mathrm{O}$ ethos

\footnotetext{
${ }^{10}$ É o caso de Maurice Halbwachs (1925), publicado en La mémoire collective, reeditado en 1950. Como en Nora, a tese básica reside na prioridade dos soportes sociais da memoria sobre os individuais. Esta obxectividade social é a que Nora subliña ao espacializar e concretar os cadres.
} 
dunha comunidade de transmisión como a nosa debe implicarse nestes procesos de memoria de forma activa. Pero a dimensión cultural ás veces non é a central e tamén hai que xulgar estes procesos desde a súa condición política e intervir nestas situacións activando o modelo da memoria moral. Desde logo, o Estado de dereito é unha institución de éxito para reducir a violencia interna. Porén, tamén se mostrou moi capaz de alentala no exterior. Unha memoria oficial, política, museística, cultural, conmemorativa, incapaz de facerlle fronte á verdade política do pasado, viola a nosa conciencia moral. Unha memoria política, de grupos minoritarios ou maioritarios, que non estea ao servizo de reducir a violencia, a hostilidade, e de producir estratexias cooperativas e poderes baseados na asociación, viola a conciencia moral e constitúe unha acción política perigosa que prefigura a diferenza amigo-inimigo. Situadas fronte á conciencia moral, todas as historias nacionais, que lle deron á ciencia histórica como disciplina o seu sentido forte, son moralmente sospeitosas. Os Estados e as nacións tamén foron ás veces dispositivos de produción de violencia e, desde logo, só se poden glorificar sobre a mentira e o esquecemento da conciencia moral. A única forma apropiada de facer historia nacional reside en medir as pequenas shoahs que hai detrás dos poderes reitores das comunidades políticas e o único propósito moral da historia nacional debe ser lograr unha memoria activa daquelas formas da política que levan ao conflito, ao enfrontamento, á falta de sentido da cooperación e aos desequilibrios dunha hexemonía. A historia nacional debe ser exemplar no tocante a captar o mal uso dos poderes, e debe argumentar verbo dos custos en vítimas que adoitan impulsar as políticas de poder que non están atravesadas por unha cultura do compromiso, da cooperación e do equilibrio dos intereses en loita. En suma, non está para glorificar, senón para servir a ideais políticos compatibles coa nosa conciencia moral. En realidade, a historia política, ao rexerse pola verdade, debe narrar as consecuencias da tiranía.

\section{MEMORIA ESTÉTICA E TECNOLOXÍA}

Todo isto está claro pero é pouco. Con esta análise non chegamos ao punto clave. Situados no medio de procesos mundiais de globalización económica, de 
memoria moral que lle dan forza ao sentido dos dereitos humanos, de historias estatais que reforzan o sentido da comunidade política, de historias nacionais minoritarias que teñen que impugnar tanto os procesos globais como os relatos das grandes nacións, os grupos humanos non teñen xa unha relación unívoca co pasado. Isto significa que non hai comunidades coactivas, de obrigada pertenza. A memoria é libre, pero por iso moito máis necesaria, xa que non hai grupo ningún que a asegure pola súa mera existencia. Todos os grupos disputan o tempo, porque agora todos ameazan o futuro de todos. Como a insistencia en asegurar a memoria procede da profunda conciencia da súa fraxilidade, ese perigo endémico xerou a necesidade igualmente xeral da memoria. Pero como xa non hai comunidades coactivas, é o individuo o que ten a responsabilidade de elixir as súas comunidades de referencia. E isto implica a responsabilidade de construír a súa propia memoria ou memorias. Os grupos implicados na defensa do patrimonio moral da humanidade, os Estados-nación, os candidatos a Estados-nación que teñen que enfrontarse aos Estados existentes, os grupos implicados na resistencia contra a globalización, todos compiten por atraer a atención dos individuos que libremente elixen comunidades de pertenza, fórmanas e organízanas mediante a creación dunha memoria correspondente. Todos compiten por controlar o espazo da memoria. Todos activan o sistema de memoria cultural para impedir o peor: a soidade e a melancolía. Isto determina que un futuro cada vez máis ignoto sexa compensado cunha mobilización infinita do pasado. E a esta necesidade da conciencia de perigo xeral, desde o grupo especie humana ao grupo máis ínfimo que poidamos imaxinar, deu a súa resposta á tecnoloxía. A nosa sociedade contestoulle á impresión xeral de risco cunha memoria cultural hipertrofiada.

E é aquí onde a variable da tecnoloxía, a súa necesidade e a súa limitación adquiren especial relevancia. Pois como acontece con todos os fenómenos sociais relacionados coa técnica, o que parecía un mero medio, destinado a asegurar necesidades, convértese nun obxectivo que impón as súas propias. Esta proliferación da técnica é consecuencia da súa imperfección, pero tamén da demanda universal de memoria. Como non existe técnica ningunha que acabe por ser perfecta, porque toda ela é limitada fronte aos obxectivos que o home persegue -a felicidade compartida e perenne-, ten que proliferar. Iso que se chama progreso é o índice da imperfección insuperable. Todas as técnicas responden a esixencias 
humanas, pero pronto se desligan dos seus obxectivos e deveñen en artefactos autónomos dotados do seu propio poder. Porque non hai técnica ningunha suficientemente perfecta como para facer que recordemos, ten que contentarse con producir arquivos onde a lembranza sexa unha posibilidade. Este sinxelo feito -garantir a posibilidade da lembranza- provoca que os arquivos se convertan en universais e infinitos. Pero garantir a posibilidade da lembranza é a resposta axeitada a unha representación do ser humano como aquel que libremente constrúe a súa memoria e que libremente se vincula a grupos.

Ao facelo, prescinde dos seres humanos e das súas demandas concretas. A oferta de memoria vai por diante da demanda porque ninguén sabe o que requirirá o futuro. Cando vemos Berlín tras os bombardeos de 1945, sabemos que esa imaxe constitúe a radiografía dunha posibilidade do noso mundo. Iso leva ao goberno alemán a construír o maior refuxio antiatómico para depositar alí o seu patrimonio cultural, do mesmo xeito que os mormóns de Iuta organizan o maior depósito de nomes propios no seu afastado deserto. $\mathrm{O}$ máis paradoxal destes supostos reside en que se acumula memoria mesmo para o caso de que non sobreviva ninguén para recordar. Que a desaparición do ser humano estea incluída no plan destinado a asegurar a memoria posible mostra tanto a eficacia da técnica como a súa mesma impotencia. No fondo non temos que agardar por unha Apocalipse nuclear, ou a inundación climática, para comprobar este paradoxo. $\mathrm{O}$ capitalismo mundial e a evolución técnica aseguran a preservación de todo o patrimonio de sentido mundial existente no presente, aínda que esa preservación e almacenamento non poidan ser recordados por ninguén. Ao contrario da perfecta adaptación da escritura para lembrar o que non se nos permite esquecer, a nova tecnoloxía - coa súa vontade de infinito- é o maior obstáculo para permitir a memoria do que é necesario. Ante esta memoria sen lembranza, un bota de menos a última imaxe de Farenheit 451, onde cada personaxe encarnaba un libro que sabía de memoria. Poñer nas mans dun ser humano esa posibilidade concreta concirne de maneira máis esencial o noso oficio de bibliotecarios que organizar un infinito repositorio que nunca será percorrido por ninguén.

Como é natural, a tecnoloxía así construída conta co usuario ideal, o individuo que xulga o interesante desde o seu propio criterio e actualiza ese repositorio desde os incontables azares que asume. Christopher Lasch caracterizou este 
individuo da sociedade postindustrial como un narcisista. Nun universo infinito onde non hai camiños pautados, nin formas preferentes de recordar, a relación entre suxeito e arquivo é azarosa e depende sempre dunha decisión narcisista; é dicir, que parte do propio desexo. Para que na Wikipedia exista a entrada que cada un busca, ten que haber individuos afíns con intereses afíns. A harmonía preestablecida entre suxeitos ten tantas máis posibilidades de exercitarse canta máis información sobre os seus desexos circule na rede. Con iso desaparece todo o que constituía a vella forma de comunidade, coa lembranza do necesario, do orixinario, do arquetípico, do imprescindible. Fronte á posibilidade de constituír o individuo desde a memoria colectiva, agora aparece o individuo constituído pola recepción de desexos en circulación no espazo mundial da publicidade. Ese individuo precisa a técnica como posibilidade infinita.

A importancia da noción de desexo, sobre a que se constrúe a tecnoloxía da información, coa súa promesa de apertura e de infinita dispoñibilidade, está ao servizo da construción dunha subxectividade que lle debe facer fronte á construción do presente sen auxilios de comunidades coactivas. Todos vemos no presente nu, nese tempo puro do aburrimento, aquilo do que hai que escapar. A tecnoloxía de preservación non lle serve de mediación a unha lembranza que xa é libre decisión do suxeito. Sérvelle a todo desexo posible de recordar. Se fose posible escapar do aburrimento mediante o expediente de explorar o que aínda non se experimentou, seguro que o fariamos. As esixencias de superar a perda, a melancolía, a desvalorización implícita na repetición, porén, impoñen a necesidade da memoria na procura dun pasado máis perfecto que o presente e capaz de darlle enerxías outra vez.

Así que entre o arquivo de preservación mundial de contidos e o individuo entregado ás formas propias de superar o aburrimento xa non hai orde ningunha. Este é o fenómeno que está na base da conversión das bibliotecas, dedicadas de forma clásica ao canon da literatura nacional ou mundial, en lugares de mediación pública coa industria do lecer. A memoria privada perdeu toda conexión cunha memoria arquetípica de natureza pública. A subxectividade rebelouse no exercicio da lembranza. Foucault sinalou que as formas de produción de bens actuais non poden funcionar sen liberdade. Isto hai que aplicalo de forma central aos sistemas á disposición da lembranza. Esta indisciplina, curiosamente, queda compensada polo simple feito de que a liberdade é exerci- 
da dentro dos esquemas e escenarios que nos propón a industria mundial na que todas as comunidades se disputan os seres humanos que permitan pasar da memoria pasiva á funcional e activa. Por iso falamos dunha indisciplina disciplinada ou dunha disciplina liberal.

Este é un escenario inquietante que ten a súa mellor garantía na pluralidade de interpretacións da liberdade. Sen dúbida, para moitos, esta relación directa e libre entre o repositorio mundial e o desexo individual, entre a memoria estática como arquivo mundial e a lembranza persoal, equivalerá á disolución das historias sagradas comúns. Neste sentido, tenderá a aplicarlle ao noso tempo a metáfora da novela de Segalen. As historias de identidade colectiva esqueceranse, simplemente porque os que as tiñan que escoitar perderon o interese ou están durmidos ou aburridos. Cando espertan, bendicen a nova casa do Señor, ese templo da aceleración mundial da información dixital que nos asegura a última forma da experiencia plena do presente: matar o aburrimento, matar o tempo, outra forma de matar a Cronos. Posto que aquí hai unha necesidade antropolóxica, un apenas se pode lamentar diso.

Así e todo, non hai solipsismo posible. Non nos cabe dúbida dun principio filosófico: calquera interpretación da liberdade que fagamos alcanza unha dimensión social inevitable. A liberdade do ser humano é o imitable e o que produce o desexo de ser imitado. Un acto libre produce unha proliferación de secuelas, de imitacións, de ecos. Este feito da mimese ten unha base neurolóxica: as neuronas que se activan cando vemos facer algo son tamén as que se activan cando o facemos. Sentir pracer cando se ve algo implica as mesmas conexións de neuronas que nos dan pracer ao facelo. A mimese ten como base biolóxica as neuronas espello. Debido a isto, a pluralidade das interpretacións da liberdade garante a pluralidade das formas sociais. E non existe forma de proliferación social da liberdade, non existe grupo con experiencia da súa formación, consciente do seu pracer, que non se xulgue como un acontecemento digno de ser recordado. Sabémolo hoxe. A tecnoloxía que nos permite canalizar as formas sociais da liberdade inclúe xa a tecnoloxía da memoria que garante as pegadas mnemómicas do acto. Concertos, manifestacións, movementos, espectáculos, celebracións, non hai acto social relevante que non planifique a forma en que se vai conservar na memoria. $\mathrm{O}$ que era unha dimensión exclusiva da propaganda do Estado total, coa súa intensificación de sentimentos da adhesión e fidelidade 
das masas, xeneralizouse, na procura sempre de manter as respostas emotivas do suceso, xa desde a mesma existencia do evento. A despolitización é a consecuencia inevitable de fidelidades a outros grupos diferentes do Estado. O que só lle servía á formación da identidade política, agora reocupouse por dispersos acontecementos, cada un coa súa solicitude de adhesión, de afecto e de memoria identitaria. A narración do acto é contemporánea coa súa realización e o seu paso ao arquivo da memoria. Chámaselle a isto produción e ten como consecuencia que o evento sexa unha ficción técnica que xa está pensada para ser recordada.

\section{RESPONSABILIDADE E RUÍDO DE ARQUIVO}

Recapitulemos o panorama. Formas de lembranza destinadas á configuración dunha memoria moral da humanidade; formas de lembranza destinadas á formación dunha memoria política de grupos con cadanseu mito político -acotío enfrontados á conciencia moral-; formas de lembranza destinadas á formación de grupos constituídos desde a proliferación mimética de interpretacións da liberdade e do interesante, con grupos que podemos chamar asentados en memoria estética. Son as tres grandes variables da memoria e as tres grandes formas de constituír identidade. Moral-relixiosa, política-mítica ou estética constitúen unha orde que vai desde o recoñecemento da unidade do xénero humano ata a existencia de sociedades fráxiles e temporais, fragmentarias e parciais baseadas en experiencias consideradas interesantes. Todas elas xogan con todas as dispoñibilidades técnicas que permite a industria e móvense nun espazo disposto pola expansión capitalista como arquivo posible. Ningunha delas pode, obviamente, ser melindrosa respecto dos medios. En Lemure un pode baixar tanto $A$ lista de Schindler, os grandes concertos dos grupos de rock ou os libros que compoñen o canon da literatura nacional, os vídeos das sociedades cerimoniais estatais ou os anuncios de Alcaeda. $\mathrm{Na}$ rede parapétanse os terroristas globais, os gobernos coas súas propagandas oficiais, os grupos independentistas cos seus contornos de activistas ou os fans de Rosendo. O arquivo é democrático e ao estaren obrigados a xogar neste contorno todas as propostas de construción da memoria xa recoñeceron a súa derrota ante o verdadeiro vencedor. Todas dependen do 
usuario, é dicir, de que alguén queira pasar da memoria estática, como arquivo, á memoria activa, como lembranza.

A característica de todo este escenario é que non se estabiliza memoria ningunha. Xa non hai poder na terra para ofrecer a versión oficial. Sempre unha posibilidade alternativa se abre camiño. Entre o que se chamou «museificación da memoria» e o "act of transfer» mesmo non hai máis que mediacións azarosas. $\mathrm{O}$ pasado, mesmo o persoal, sempre é un pasado mediado -mediado polos media, desde logo, pero non hai mediación representativa, coactiva, única, aceptable (Jedlowski, 2007, p. 42). Os poderes teñen peso, pero ningún ten por si mesmo a hexemonía. O éxito da serie Cuéntame reside xustamente en que facilita a lembranza de moita xente, á que, ademais, lle impón a opción de lembrar, pero non pode evitar que Supervivientes á mesma hora lle quite unha audiencia masiva porque son moitos máis os que están dispostos a matar o seu aburrimento vendo como outros se aburren. Por moi central que sexa un programa da televisión para definir o pasado público, sempre queda a alternativa de programas que se caracterizan por propoñer outro ou por reunir aos que non queren ter pasado. O soño de crear un sentido común homoxéneo a través dos media é puro pasado. Como sabemos demasiado ben, os media medran en poder cando, como todo poder, organizan o espazo dividido en amigo e inimigo. Afortunadamente, a dispersión impide a concentración dualista e permite a proliferación da liberdade. A proliferación dos seus actos duplícase como proliferación de arquivo e así permite a proliferación da heteroxeneidade da memoria.

Esta situación non é nova nin única. O ser humano individual repite estruturas que veñen existindo na especie durante miles de anos, como na especie se repiten estruturas que veñen xogando desde a orixe da vida. $\mathrm{Na}$ especie máis evolucionada amoréanse os triunfos da evolución realizados desde o principio. Pero o sentido da evolución non é unívoco. Hoxe sabemos que se o final da evolución consistía en aumentar as posibilidades de transmisión da propia carga xenética, un dos resultados non previstos dese triunfo evolutivo consistiu en aumentar a duración da vida. Curiosamente, este resultado inverte a meta final, pois xa non contribúe a reproducir o arsenal xenético, senón a eliminalo con poboacións avellentadas. Pero non só iso. Éxitos evolutivos que eran funcionais para unha vida curta convertéronse en fontes de problemas para a vida cando esta se fai máis duradeira. Hai algo así como un tempo previsto polos mecanis- 
mos evolutivos xenéticos e semella que unha vida máis longa os obrigará a unha aprendizaxe diferente aos nosos xenes.

Tras as investigacións de Claudio Franceschi, sabemos que hai unha alta probabilidade de que isto aconteza cos mecanismos da memoria inmunolóxica (2007, p. 243-269) ${ }^{11}$. Posto que os anticorpos non responden univocamente aos axentes patóxenos, senón a unha serie ordenada de afinidades, ao ter unha vida humana longa, a formación de exércitos de anticorpos con memoria de patóxenos é tan grande que, ante unha infección, esas células de memoria por si mesmas producen infeccións basais que poñen en perigo a propia vida que tiñan que defender. Como, ademais, a resposta destes anticorpos é ante series afíns, é doado que ante unha infección se activen moitos anticorpos ao mesmo tempo, no que se chama ruído inmunolóxico. Quizais isto que acontece coa memoria inmunolóxica, como consecuencia dunha vida que superou o límite previsto, e ten que administrar unha complexidade de memoria inesperada, é o que sucede co ruído do arquivo. Poñer en acto unha dimensión do arquivo mobiliza tal cantidade de información inespecífica que a lembranza nítida resulta imposible. $\mathrm{O}$ acto destinado a recordar frústrase por exceso de lembranza. $\mathrm{O}$ dispositivo destinado a protexer mata. A aprendizaxe xenética que se quere inducir só pode implicar un esquecemento selectivo. Pero como identificar a selección daquilo que queremos esquecer se non temos unha conciencia precisa do perigo? E quen decidirá o que debemos dar a esquecemento nos nosos xenes? Unha educación xenética lévanos aos mesmos problemas de toda educación: que obxectivos desexamos facilitar. E como sempre ante esta pregunta a técnica cala.

$\mathrm{O}$ noso mundo de percepcións actuais tivo éxito sobre o control da complexidade. Pero sabemos que iso pasa cando nos limitamos á superficie dun mundo de complexidade infinita. Se ese infinito emerxe ata o presente actual, todo se converte en fráxil e ruidoso. Administrar todo o posible é imposible e sobre iso construíu Borges os paradoxos da súa obra enteira. Iso é o que acontece sobre o arquivo e sobre a imposibilidade de administralo como memoria cando o dinamismo se entrega aos infinitos actos libres individuais e a oferta,

\footnotetext{
11 Tamén se pode ver o seu traballo (2002, p. 81-100). Ten, ademais, unha gran cantidade de traballos
} sobre o seu concepto central «Immunosenescence». 
polo tanto, ten que abarcar todo o posible. Ninguén ten dereito a decidir que é o que se debe esquecer. Pero aínda así non resolvemos o problema. Sabiamos que ethos aplicar á nosa comunidade coa memoria moral, coa memoria política, pero ambas as dúas son cada vez máis desprezables respecto á memoria que mata o aburrimento, a memoria estética. O paradoxo da nosa específica situación social móstrase aquí en toda a súa crueza. Unha sociedade centrada na memoria estética -en matar o aburrimento- esquece aquilo que fai posible entregar a liberdade a matar o aburrimento: as condicións de vida morais e políticas adecuadas. Así unha sociedade como a nosa está disposta a esquecer o que é a propia condición necesaria do seu gozo. Se o poder non é o "control dos comportamentos, senón sobre as súas precondicións» (Melucci, 1999), daquela o poder real desapareceu, porque ninguén asegura a memoria das precondicións do universo da liberdade.

Así que a cuestión que lle concirne ao ethos da nosa profesión pregunta en termos de que non podemos esquecer baixo concepto ningún. Isto conéctase co feito de que as nosas sociedades teñen máis usuarios da liberdade que defensores das súas precondicións. Sen memoria para esas precondicións, entramos en zona de perigo. Quizais aí teñamos como profesións de transmisión o noso ethos. A consecuencia para a memoria estética consiste en que non podemos permitila cando implique violacións da memoria moral ou da verdade política, cando se esteticen as vítimas ou se faga proliferar a mentira porque é máis divertida que a verdade. Os valores morais e políticos fundamentais, relacionados coa limitación da violencia e a solución pacífica dos conflitos, condicionan a memoria estética, onde non todo está permitido. Pero mesmo nesta orde da memoria cultural e as súas dimensións estéticas tócanos algunha responsabilidade. Aquí, unha vez máis, quizais o esquema da bioloxía sexa aplicable non só para coñecer os custos de ruído dunha longa vida, senón para identificar aquilo que ten unha pegada psíquica máis arcaica, e realizar unha verdadeira historia cultural identificando as enerxías dalgunhas imaxes sobre a nosa capacidade para gozar. No fondo, iso é o que pretenden os estudos culturais desde Warburg e por iso teñen como vértebra a cuestión da memoria. No fondo, eses estudos culturais non fan máis que configurar comunidades de historia-memoria, anticorpos que identifican as estruturas patóxenas do noso presente e nos alertan contra os grandes perigos 
da especie humana, unha humanidade sen conciencia moral, sen conciencia política e sen conciencia estética. En resumo, unha humanidade que aspire a resistir esa situación que, a un profundo coñecedor do noso mundo como Max Weber, xa lle parecía a vida inaceptable de especialistas sen espírito ou de estetas sen corazón. 


\section{BiBLIOGRAFíA}

AgAZZI, E.: Vita fortunati, memoria e saperi, Percorsi transdiciplinari, Roma, Universale Meltemi, 2007.

AssmanN, J.: «Frühe Formen politischer Mythomotorik. Fundierende, kontraprësentische und revolutionäre Mythen», en Harth, D. e J. Assmann: Revolution und Mythos, Frankfurt, Fischer, 1992, p. 39-61.

Assmann, J.: «Die Gleichzeitigkeit des Ungleichzeitigen. Nationale Diskurse zwischen Ethnisierung und Universalisierung», en U. BIELEFELD e G. ENGEL: Bilder der Nation. Kulturelle und politische Konstruktionen des Nationale am Beginn der europäischen Moderne, Hamburgo, Hamburger Edition, 1998, p. 379-400.

Assmann, J.: Erinnerungsräume. Formen und Wandlungen des kulturellen Gedächtnisses, Múnic, Beck, 1999.

Assmann, A.: Ricordare. Forme e mutamenti della memoria cultural, Boloña, Il Mulino 2002.

Assmann, J. e T. HÜLSCHER: Kultur und Gedächtnis, Frankfurt, 1988.

Behrenbeck, S.: Der Tode und die toten Helden. Nationalsozialistische Mythen, Riten und Symbole, Múnic, Fink, 1996.

Bielefeld, U. e G. ENGel: Bilder der Nation. Kulturelle und politische Konstruktionen des Nationale am Beginn der europäischen Moderne, Hamburgo, Hamburger Edition, 1998.

CAHIER de l'Herme, París, edicións de L'Herme, 1998.

Connerton, P.: How Societies Remember, Cambridge, Cambridge University Press, 1989.

Destro, A. e M. Pesce: Come nasce una religione. Antropologia ed esegesi del Vangelo di Giovanni, Roma, Laterza, 2000.

FlooD, C.: Political Myth. A Theoretical Introduction, Londres, Routledge, 1996.

FRANCESCHI, C.: «La memoria immunologica come paradigma delle memorie biologische», en E. AGAZZI: Vita..., op. cit., p. 243-269.

FrANCESCHI, C.: «Invecchiamento e complessità: una prospettiva evolutiva», en P. DONGHI: La Nueva Odissea, Bari, 2002, p. 81-100.

GomBrich, E.H.: Aby Warburg, An Intellectual Biography, Londres, The Warburg Institute, 1970. Hai tradución en Alianza Universidad.

HalbWaCHS, M.: Les cadres sociaux de la mémoire, París, 1925, reeditado en 1950.

HaRTh, D. e J. Assmann: Revolution und Mythos, Frankfurt, Fischer, 1992.

HERVIEU-LÉGER, D.: La religion pour mémoire, París, Cerf, 1993.

Jedlowski, P.: «Memoria e interazioni sociali», en E. AgazZi: Vita..., op. cit., p. 31-45.

Koselleck, R.: Futuro Pasado, Barcelona, Paidós, 1993.

LECCARDI, C.: «I tempi di vita tra accelerazione e lentezza», en F. CRESPI, Tempo vola. L'esperienza del tempo nella società contemporanea, Boloña, Il Mulino, 2005, p. 49-85.

LECCARDI, C.: «Memoria e responsabilità come forme della durata», en E. AGAZZI: Vita..., op. cit., p. 117-134 .

Levinson, B.: «¿Es el antisemitismo un racismo?», Res Publica, Revista de Filosofía Política, 13-14 (2004), p. 9-29.

Mauceron, G.: Segalen, París, Lattès, 1991.

MeluCCI, A.: «Diventare persona. Nuove frontiere per l'dentità e la cittadinanza in una società planetaria», en C. LECCARDI (ed.): Limiti della modernità. Trasformazioni del mondo e della conoscenza, Roma, Carocci, 
1999, p. 123-145.

MотTA, F.: «Elementi di una memoria fondativa del cristianismo», en E. AGAZZI: Vita..., op. cit., p. $712-$ -734 .

Nora, P.: Les lieux de la mémoire, París, Gallimard, 3 vols., 1984-1992.

SCIOLLA, L.: «Memoria, identità e discorso pubblico», en M. RAmpaZI e A. L. TOTA: Il linguaggio del passato. Mass media, memoria e discorso pubblico, Roma, Carocci, 2005, p. 19-30.

Segalen, V.: Les immemoriaux, París, Plon, 1956.

Segalen, V.: Le isole dei senza memoria, tradución de Michela Baldini, Roma, Biblioteca Meltemi, 2000.

Siebert, R.: «Memoria e giustizia», en E. AgAZZI: Vita..., op. cit., p. 79-99.

Smith, A. D.: Chosen Peoples. Sacred Sources of National Identity, Oxford, Blackwell, 2003.

Stroumsam, G.: La formazione dell'identitá cristiana, Brescia, Morcelliana, 1999.

Todorov, T.: Les abus de la mémoire, París, Arléa, 1995.

TотA, A. L.: «Memoria, patrimonio culturale e discorso pubblico», en E. AgAzZI: Vita..., op. cit., p. $102-$ $-113$.

TUTU, D.: No Future without Forgivennes, Nova York, Doubleday, 1999. 